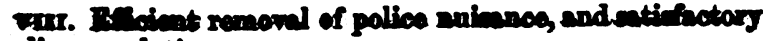
police regulations.

Ix. Bducation of cholere nunes, to be drafted from woxkhouses and public charities.

x. Honse to house visitation during epidemic cholern. II. Frection of the choler hospitals formerly allinded to.*

Yurray's Royal Asylum, Perth, Norember 185t.

\section{CASE OF FRACTURE OF THE BASE OF THE SKULL: RECOVERY.}

By GEORGE BIDIE, M.B. and L.R.C.S.E.

On Sunday, the 21 st of May, while visiting a patient in the country, I was hastily summoned to see a lad in the fohing village of Findochty, who had met with a serious accident. On my arrival, I learned that the sufferer, a young fisherman, aged 16 years, had been reclining upon the brink of a crag in the neighbourhood; and that, on getting up "to stretch himself", he had lost his equilibrium, and fallen down a height of from twenty to thirty feet. The head had first come in contact with the ground, and there was a deep ragged scalp wound stretching from right to left across the occipital protuberance. This gap had bled profusely; and on washing away the clots that hung in the hair, I discovered a copious hæmorrhage welling up from the left ear. The discovery of this hæmorshage, in conjunction with other signs indicative of serious mischief, led me to suspect fracture of the base of the skull-the fracture by contre-coup. To remove the more alarming symptoms of collapse was now my care-the pulse being very feeble and intermittent, and the heat of the body considerably below the natural temperature. In - little, frequent vomiting ensued; and I was gratified by seeing at any rate a partial recovery established. By this time, the bleeding from the ear had completely soaked the pillow. Taking, therefore, into account the aggregate loss of blood, I was led to consider further depletion unnecessary. No fracture could be detected at the site of the scalp wound, and the other parts of the body amenable to an outward examination seemed quite intact. I now cut the hair as close as possible, approximated the edges of the wound with strips of adhesire plaster, and had the head elevated upon pillows, with orders that it should be kept constantly covered with cloths wrung out of cold water. Before leaving for the night, I administered twelve grains of calomel rubbed up, as the power of deglutition was but foeble, in a pill of fresh butter.

Monday, May 22nd, 6 o'clock A.M. During the night, my patient had relapsed into a state of insensibility nearly as profound as the primary. The skin was hot and perspiring; the pulse slow, but rising upon any attempt being made to arouse him; the breathing was slow, deep, and somewhat stertorous; the bowels had been unmoved. One drop of croton oil was put upon the tongue, and an enema of turpentine ordered. The enema was directed to be repeated at intervals. A thin watery discharge had taken the place of the hæmorrhage from the ear.

7 o'clock P.x. The second enema had been administered about 12 o'clock at noon, and brought away large quantities of freal matter. Since then, the patient had twice intimated, by intelligible signs, a wish to have the chamber utensil when the calls of nature were urgent. Any attempt, however, to arouse him from the lethargy which still continued, merely tlicited a surly "be quiet", or a wish to be let alone. The pulse was still slow; the skin cooler; and the breathing freer.

May 23rd, 12 o'clock at noon. My friend, Dr. Gerrard of Buckie, kindly accompanied me during this visit, and formed the same opinion as myself regarding the nature of the injury and imminent danger of the patient. The stupor was still persistent; the pulse slow; the skin hot. He had spent a restless night. We ordered twelve

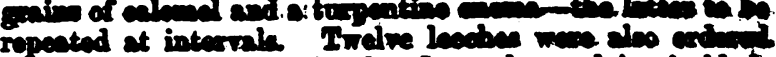
to bo applied to the farebead and temples, and ive in blut ders kept conntently upon the head.

Mas 24th, 6 o'olock 4.x. The stuper was leas marked; the pulse had improred; and the borrell had been morect freely more than once. I oxdened twelve powders, contrining in all twenty-four grains of calamel. Three of thea. powders were to be adminietered drily.

8 o'clock erening. He was ctill improving aince the morning.

From this date the pationt gradually progressed towands necovery, the treatment, with slight variations, being merely a repetition of the foregoing. The scalp wound healed kindly. During recovery he exhibited great wealmeese in the lower extremities, staggering like a paralytic on boing acsisted to the erect posture. By the l0th of June, he could with a little assistance walk from his bed to a chnir. For a time, however, after regaining the power of speech, his memory was completely upset. Like some of the Athenians, who recorered from the great plague, mentioned by Thucydides, he actually could not at one period recallect his own name, or that of a single friend. The intelligent look, however, that his features displayed upon his being asked the name of any friend, seemed to indicate the power of recognition, although memory refused to supply the correct name, and furnished instead a nomenclature the most fantastic and inexplicable. His mother was frequently called "the tongs", "the book", etc.; and hardly ever by any chance did she twice enjoy the same appellative. Repeated blisters and a seton in the neck, along with the cautious use of mercury, shortly began, however, to effect a change; and by the middle of July, he was in perfect possession of all his faculties, physical and mental.

Cullen, December 4th, 1854.

\section{$\checkmark$ \\ CASE OF SUDDEN DEATH DURING THE INHALATION OF THE VAPOUR OF CHLOROFORM.}

By JOHN BIRKETT, Esq., Surgeon to Guy's Hospital.

HАNNAH Brooks, aged 56 years, was admitted into Guy's Hospital, under my care, Nov. 15th, 1854. She said she was in good health; but she had a most cachectic appearance, was edentulous, and appeared quite ten years older than the age she represented herself to have reached. She lived in Southwark, and obtained a somewhat precarious livelihood by washing. She had had chronic ulceration of both legs the last two years, the ulceration nearly surrounding the leg, at about the junction of the middle and lower third. Two months before admission into Guy's, the ulcer on the left leg assumed a sprouting, fungating aspect, became very painful, and, during the last month, it bled frequently and profusely. In the left groin there was an enlarged gland. Various means having been ineffectually employed to destroy the cancer, amputation of the limb below the knee was proposed as the only palliative measure, and was agreed to. She drank some wine and water a short time before the administration of the chloroform. Her mind was calm and resigned, and there was no apparent depression produced by the contemplation of the operation. On Monday, the 4th of December, she seemed to be suffering from a trifling febrile attack, and said she thought she had taken cold. I told her that, if this condition existed upon the following day, we must postpone the operation. I gave her an ounce of mixture of acetate of ammonia, with fifteen minims of tincture of hyoscyamus, three times daily. On Tuesday, the 5th, she expressed herself as feeling quite well; the febrile attack had passed away; the skin, the temperature of which wh higher than the healthy standard the day before, was natural; and her tongue was slightly furred - a condition of this organ which had existed during the whole time of $\mathrm{my}$ observation of the case. A few minutes after 1 P.M., she was carried into the operating 


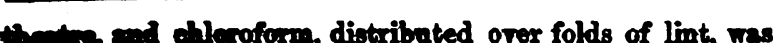
wh at abest distance from her mouth and nootrils. Buing the inhalation of the vapour, the tourniquet was adjucted over the femorsal artery. It was secured tightly fre for coconds, to ascertain if its pressure commanded the pulcations of the artery; but it was immediately after chocened. The inhalation of the vapour had been continued a minute or $t$ To, when considerable muscular movements and rigidity of the limbs resulted. These movements oubsided, and I was about to commence the amputation, when Mr. Callaway called my attention to the sudden cessation of the action of the heart. In the capacity of assistantourgeon, he held his finger upon the iliac artery; and in an instant he was conscious of the complete cessation of its puleation. I immediately began artificial respiration by pressure upon the ribs and epigastrium, while the tongue was instantly drawn forwards, and held in that position: the patient drew a deep inspiration. The treatment was continued; a second deep inspiration was made; and, after a longer interval, a third, and the last. Cold water had been dashed over the face, and galvanism applied in such a position that the current might influence the contraction of the diaphragm. Just before the cessation of the action of the heart, I observed that the veins about the neck were very full of blood, and that the expirations were performed with considerable suffiation of the cheek and sudden opening of the lips; but this condition, being a very constant attendant upon the inhalation of the rapour, was not particularly remarked upon.

The vapour was administered by means of a folded piece of lint, covered on one side with varnished silk: it had never been, during the whole time of its use, in contact with both the mouth and nostrils of the woman at the same time, but was held at a little distance from the face. Less than two drachms of the chloroform had been poured upon the lint. The temperature of the theatre was low. There was not any accurate observation taken of the time during which the patient was subjected to the influence of the vapour; but, after inquiring of several bystanders, and striking an average of their varied statements, I believe I am correct in stating the time to have been under five minutes.

The chloroform was in charge of a gentleman who had been practically experienced in its administration for a long time.

The effort of romiting had not been in the slightest degree induced; indeed, the presence of any solid food in the stomach had been particularly prevented.

Examiration of THE BoDr, twenty-six hours after death, by Dr. Wilks. The weather was cold and wet; there were no signs of decomposition; rigor mortis was present in a moderate degree. The external appearance of the body was that of $a$ woman at least ten years older than the age above indicated. The hair was quite grey; arcus senilis was present; the cheeks were fallen in from loss of the teeth. The body was spare, the skin having the smooth yellow appearance indicative of senile fatty degeneration. The stature was moderate. A chronic ulcer existed on the right leg; and on the left was a fungating mass. There was about the usual amount of blood in the brain. The membranes were healthy. The subarachnoid fluid was greatly increased in quantity; and this seemed due to its filling up parts of the cerebral surface which were wasted. The convolutions on the upper surface were shrunken, but otherwise healthy. The ventricles contained an increased amount of clear serum. One choroid plexus was vesicular. The cerebral arteries were diseased, containing numerous atheromatous and bony patches. The grey matter of the brain was of the usual colour, or perhaps slightly paler than usual. The medulla oblongata did not exhibit any morbid appearance.

The larynx and traches were healthy.

No pleuritic adhesions existed.

The bronchi were full of frothy mucus; the tubes were slightly irregular in shape; and the muscular fibres large, as if the pationt had been the cubjoot of old bronchitis.
The lungs were rery congested. A section caused s great flow of blood from the cut surface, so that the whole was-saturated. The tissue of the lungs firm and healthy.

The bronchial, mediastinal, and cervical glands, were healthy.

The pericardium contained about two drachms of serum.

The heart was of usual size and form; all its cavities were empty. The endocardium on the left ventricle had some patches and streaks of fibroid degeneration. The muscular fibre presented to the eye some of the sigrag lines of fatty degeneration. The microscope, however, showed the fibres to be slightly granular, and with a little deposit of fat. This, however, did not exist to any great extent, and was observed more on the right ventricle than the left. The whole anterior surface of the right ventricle was covered with a thin layer of yellow fat, which had encroached somer.hat upcn the muscular wall, and caused some atrophy of it. The fleshy columns of the mitral, when incised, prosented white surfaces: this was due to a fibroid change. Tine valves were thickened, opaque, and covered with atheroma, but efticient. The coronary vessels were tolerably healthy. The weight of the heart was eight ounces.

The alimentary canal was normal. The liver was very large; its surface was slightly nodulated; and the capsule was opaque. The surface of the section was slightly granular; it contained a slight increase of fat; it weighed three pounds and six ounces. A large gall-stone was found in the gall-bladder. The spleen was very soft, almost diffluent; the corpuscles were large. Its weight was seven ounces. The pancreas was healthy. The supra-renal capsules were firm and white in the centre. The lumbar lymphatic glands were healthy. The abdominal aorta was covered internally with atheroma. The kidneys were very degenerated, very hard, red, shrivelled, and uneven. Their surface was very granular, and tore after removing the capsule. They were full of eysts of all sizes. Some contained clear fluid, others a gelatinous substance. The urinary bladder was contracted; the few drops of urine it contained were highly albuminous. The tissue of the cancer on the leg showed well-marked cancer-cells, with very large nuclei. The left inguinal glands exhibited similar structures.

Wollington Street, Southwark, Dec. Sth, 1854.

\section{CASES OF SPINAL DISEASE.}

By SAMUEL H.RE, F.R.C.S.

ThE particulars of these cases present some points of considerable interest; and as they likewise exhibit, in a rery satisfactory manner, the improvement which results from the adoption of the plan of treatment I have so long advocated, I have thought it desirable to give them publicity in the pages of the Association JoURxaI.

Case i. Excurvation of tile Spise, with Irregular Argolar Projection, implicativg the whole of the Dursal Vertebre, ayd attended with Paralysis of the Lower Extremities. Miss E. W., aged 28, came under treatment in February 1852. She suffered very sererely from measles and hooning-cough when two years of age, and when seven years old had inflammation of the lungs, which continued six or seven weeks, and her health became so delicate that she was supposed to be sirongly threatened with consumption. About this time, she had a fall from a chair, and to this was attributed the deformity which subsequently took place; she suffered much from a pain extending from the chest through to the back, especially that part of it which afterwards became the most prominent. When ten or twelve years of age, she stooped considerably, and was round-shouldered, especially when she walked, and her breathing and palpitation of the heart became troublesome, and even distressing, if she exerted herself. When she was eighteen or nineteen, her walking became more and more difficult, and was attended with numbness; and she was quite unable to walk at all for six years previous to my seeing her-the lower extremities having 